\title{
Spatial distribution of Tyrophagus similis (Acari: Acaridae) in agricultural soils under greenhouse conditions
}

\author{
Shikoh Kasuga ${ }^{\dagger}$ and Hiroshi Amano* \\ Laboratory of Applied Entomology and Zoology, Faculty of Horticulture, Chiba University; Matsudo, Chiba 271-8510, Japan
}

(Received 25 February 2005; Accepted 5 April 2005)

\begin{abstract}
We investigated the horizontal and vertical distribution of Tyrophagus similis in agricultural soils in two greenhouses between May 1997 and May 1998. Tyrophagus similis inhabited not only the cultivated soil, but also the uncultivated soil in the periphery of the cultivated area inside the greenhouse and the soil immediately outside the greenhouses. The mite density in the cultivated and peripheral soils increased in the cooler months and decreased in the warmer months. We collected only small numbers of $T$. similis from the adjacent outside soil during the survey period. In the cultivated soil, most $T$. similis inhabited soil at depths of $0-5 \mathrm{~cm}$ throughout the year, and their numbers decreased with depth. These results suggest that the main control point of $T$. similis is the $0-5-\mathrm{cm}$ soil layer in cultivated and peripheral soils of the greenhouse.
\end{abstract}

Key words: Pest management; population dynamics; spatial distribution; spinach; Tyrophagus similis

\section{INTRODUCTION}

To predict arthropod pest's population dynamics, spatial distribution of the pests with their seasonal prevalence must be determined. Additionally, it is important to know a pest's distribution, because the habitat distributions of pests are often connected directly to their control points. For instance, aphids, thrips, spider mites and many other agricultural pests inhabit plants or the surrounding area and can cause damage to other plants nearby. This is also true of vegetable-feeding acarid mites, including Tyrophagus similis Volgin. Tyrophagus similis is a serious mite pest of the greenhouse spinach Spinacia oleracea L. in the cooler months in Japan (Nakao, 1989; Kasuga and Amano, 2000b). These mites initially increase in number on, or in, cultivated soils rich in organic matter, and they subsequently invade the spinach buds and feed on the young leaves (Kasuga and Amano, 2003). As the plants grow, the damaged leaves begin to show small holes and deformation. Damage by T. similis is observed mostly in the early spring and late autumn, when greenhouse temperatures are generally moderate. Tyrophagus similis is generally controlled by agrochemicals, but in many cases the effects of these chemicals are unsatisfactory (Kasuga and Amano, 2000b). One of the reasons for this control failure is a lack of knowledge about the spatial distribution of $T$. similis. The aim of this research was to describe the horizontal and vertical distribution of $T$. similis in greenhouse soils in order to develop an effective management strategy for this mite.

\section{MATERIALS AND METHODS}

Greenhouses. We investigated the spatial distribution of T. similis in two greenhouses (A and B, Fig. 1) in Koshigaya, Saitama Prefecture, central Japan $\left(35^{\circ} 53^{\prime} \mathrm{N}, 139^{\circ} 50^{\prime} \mathrm{E}\right)$, between May 1997 and May 1998. The greenhouses were each $50 \times$ $5.4 \mathrm{~m}$ and had no heating or cooling facilities. The entire area of each greenhouse, except for the pathways and a border area around the insides of the greenhouse walls (the peripheral soil area), was

\footnotetext{
* To whom correspondence should be addressed at: E-mail: amano@faculty.chiba-u.jp

$\dagger$ Present address: Laboratory of Entomology, Department of Fruit Vegetables, National Institute of Vegetable and Tea Science, Ano, Mie 514-2392, Japan

DOI: $10.1303 / \mathrm{aez} .2005 .507$
} 


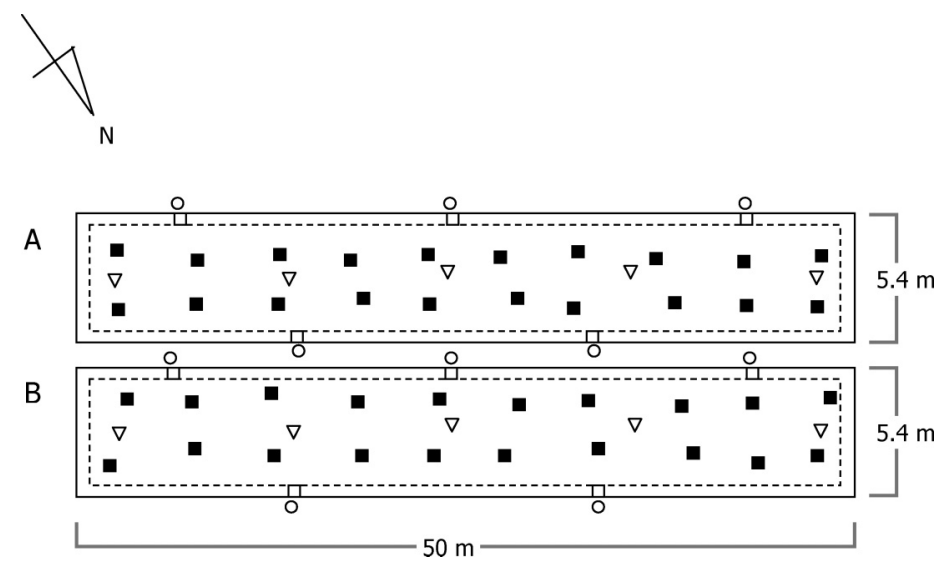

Fig. 1. Ground plan of the survey greenhouses (A and B) and sampling points. Solid frames show the area of each greenhouse and dashed frames inside the solid frames show the cultivated area planted with spinach. Soil samples to determine the horizontal distribution of Tyrophagus similis were taken from the cultivated area (closed squares, 20 points), peripheral area (open squares, 5 points), and adjacent outside area (open circles, 5 points) between June 1997 and May 1998. Soil samples to determine the vertical distribution of $T$. similis were collected from the cultivated area (open triangles, 5 points $\times 4$ vertical levels) in each greenhouse between May 1997 and May 1998.

used for growing spinach plants. Spinach was cultivated throughout the year with minimum use of agrochemicals (maximum of two agrochemical administrations per cultivation period). The length of time between sowing and harvest depended on the season: it was about $1 \mathrm{mo}$ in summer and 2 or 3 mo in winter. Sufficient irrigation until the soil reached maximum water-holding capacity was usually provided just before sowing in each greenhouse, and no additional water was supplied during the growing period except when the soil water content fell to the wilting point. The spinach variety grown changed with the season: 'Active' was grown from mid-April to July, 'Pandora' in August and September, 'Atlanta' from October to January, 'Mistral' in February and the first half of March, and 'Platon' from mid-March to mid-April. In the two greenhouses, spinach damage by $T$. similis had become more serious in recent years, possibly because of the overuse of organic fertilizers. Rice chaff and beer cake had been used in these greenhouses for several years. In the greenhouses, organic matter made up about $5-10 \%$ of the soil volume. A description of the agrochemicals used in the greenhouses during the survey seasons, and their effects, were given in a previous paper (Kasuga and Amano, 2003). During the mite season (from October to April), dichlorvos emulsifiable concentrate (EC), permethrin EC, phenthoate EC and DCIP (bis(2-chloro-1-methylethyl)ether) granules $\left(30 \mathrm{~kg} / 1,000 \mathrm{~m}^{2}\right)$ were applied in greenhouse
$\mathrm{A}$, and dichlorvos $\mathrm{EC}$, permethrin $\mathrm{EC}$, phenthoate EC, small amounts of DCIP granules $(5 \mathrm{~kg} / 1,000$ $\mathrm{m}^{2}$ ) and pyraclofos granules were applied in greenhouse B. Kasuga and Amano (2003) showed that dichlorvos and pyraclofos had pronounced acaricidal activity on T. similis, and that phenthoate and DCIP were likely to have a repellent effect.

Sampling, extraction and counting of mites. Surveys were conducted approximately every 2 wk. Soil samples were taken with a metal cubic sampler $\left(100 \mathrm{~cm}^{3} ; 5 \mathrm{~cm}\right.$ long $\times 4 \mathrm{~cm}$ wide $\times 5 \mathrm{~cm}$ high) from each greenhouse to determine the spatial distribution of T. similis (Fig. 1). Twenty samples to evaluate the horizontal distribution of $T$. similis were taken from the cultivated area inside the greenhouse, five from the soil at the periphery of the cultivated area, and five from the adjacent area outside the greenhouse. Soil samples to determine the vertical distribution of the mites were taken from the $0-5,5-10,10-15$ and $15-20-\mathrm{cm}$ soil layers (four vertical depths) in the cultivated area after the ground had been dug down to a 30$\mathrm{cm}$ depth at five different points. Soil samples were put into plastic bags and transported to the laboratory inside opaque plastic containers without direct exposure to daylight. Mites were extracted in a Tullgren funnel with a $40 \mathrm{~W}$ bulb over $3 \mathrm{~d}$. In our preliminary experiment (data not shown), we confirmed that this apparatus could dry soil samples and complete the extraction of $T$. similis within $3 \mathrm{~d}$. The mites extracted using the Tullgren funnel were 


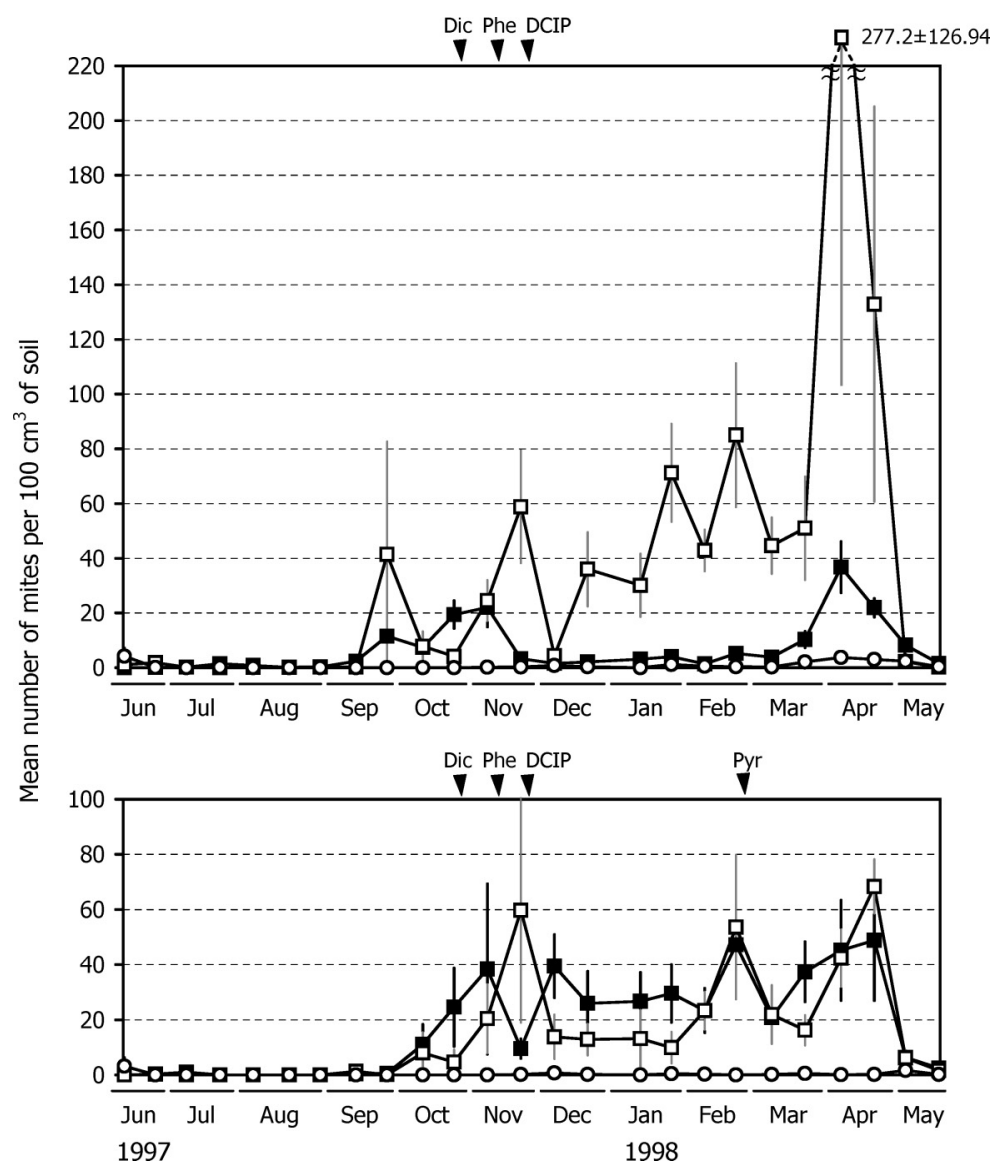

Fig. 2. Population dynamics of Tyrophagus similis in cultivated soil (closed squares), peripheral soil (open squares), and outside soil (open circles) of greenhouse A (upper panel) and greenhouse B (lower panel) from June 1997 to May 1998. Each bar indicates \pm SE. Arrows indicate the times of application of agrochemicals for pest control in each greenhouse. Dic, Phe, DCIP and Pyr above the arrows indicate dichlorvos EC, phenthoate EC, DCIP granules and pyraclofos granules, respectively. Greenhouses A and $\mathrm{B}$ received regular and low amounts of DCIP granules, respectively.

counted under a stereoscopic microscope. Specimens were mounted on glass slides so that the species could be identified (Nakao, 1996) under a phase-contrast microscope. For the assessment of horizontal distribution, the numbers of mites in the cultivated and peripheral soils were subjected to the Mann-Whitney $U$-test at a significance level of 0.05 .

\section{RESULTS}

\section{Seasonal prevalence and horizontal distribution of $T$. similis}

Figure 2 shows the seasonal population changes in T. similis in the cultivated soil, peripheral soil and outside soil for greenhouses A (upper panel) and B (lower panel). Tyrophagus similis inhabited all of these areas. However, only small numbers of mites were collected from the outside area throughout the year. The mite densities in the cultivated and peripheral soils increased in the cool months, but were low in the hotter months. Nevertheless, T. similis was collected from the greenhouse soil every month.

In greenhouse A (Fig. 2, upper panel), mite numbers in the cultivated and peripheral soils began to increase from late September. Mites in the cultivated soil decreased after the application of agrochemicals in October and November, but mite numbers increased again in March and April. In the peripheral soil of greenhouse A, T. similis numbers gradually increased from September to March and then increased rapidly in April. In May, T. similis numbers in the cultivated and peripheral soils rapidly decreased. The mite density in the peripheral soil was higher than that in the cultivated soil 


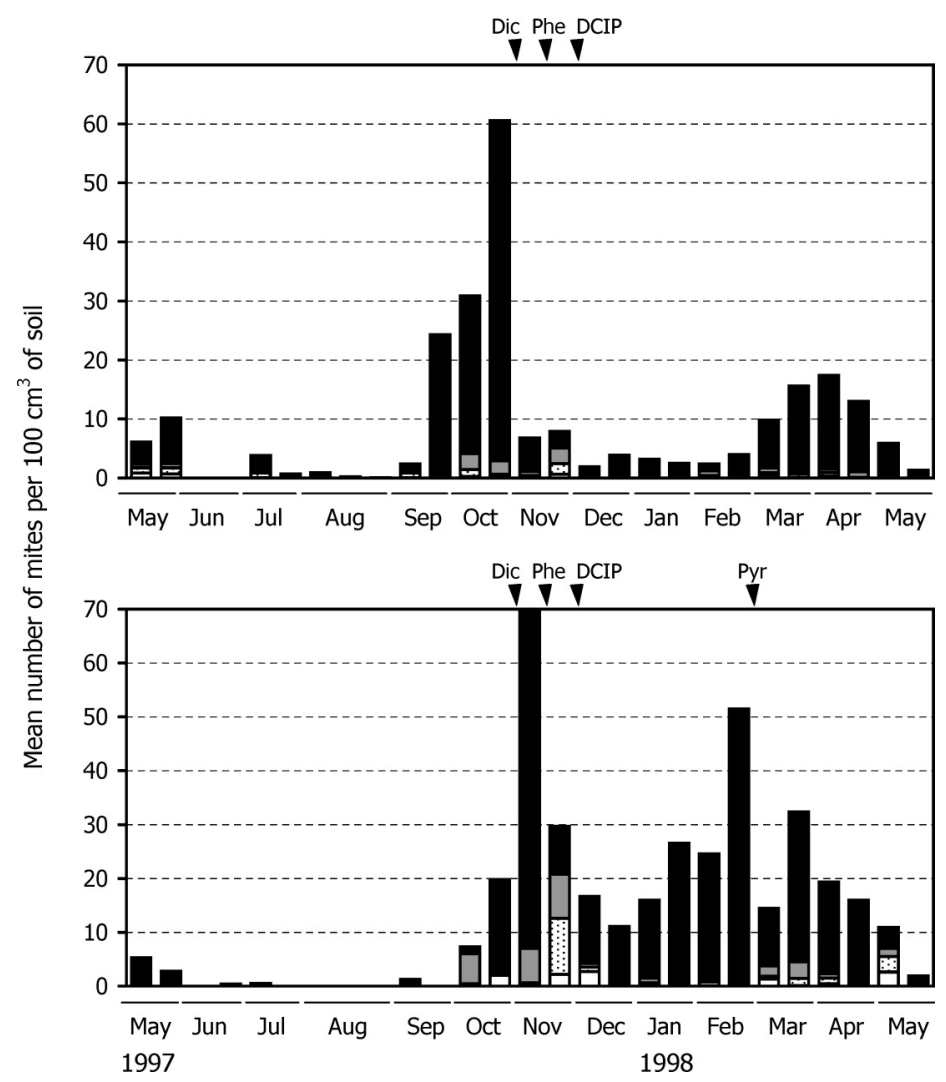

Fig. 3. Vertical distribution of Tyrophagus similis at 0-5 cm (black bars), 5-10 cm (gray bars), 10-15 cm (white bars with black dots) and 15-20 cm (white bars) below the cultivated soil surface in greenhouse A (upper panel) and greenhouse B (lower panel) from May 1997 to May 1998. Arrows indicate the times of application of agrochemicals for pest control in each greenhouse. Dic, Phe, DCIP and Pyr above the arrows indicate dichlorvos EC, phenthoate EC, DCIP granules and pyraclofos granules, respectively. Greenhouse A received a regular rate of application of DCIP granules and B received a low rate.

after the application of agrochemicals, and significant differences in mite numbers were observed between the cultivated and peripheral soils on 21 June, 18 July, 24 October, 21 November, from 19 December to 20 March, and on 1 May and 15 May (Mann-Whitney $U$-test, $p<0.05$ ). In greenhouse $\mathrm{B}$ (Fig. 2, lower panel), the mite density in the cultivated soil was relatively high during the cool months because the application of the small amount of DCIP was not effective. In February, mite numbers increased again and pyraclofos granules were applied. Thereafter, T. similis numbers in the cultivated and peripheral soils increased from March to April and then rapidly decreased in May. In greenhouse $\mathrm{B}$, the density patterns of mites in the cultivated and peripheral soils were parallel, and no significant differences in mite numbers were observed between these two soil areas throughout the year (Mann-Whitney $U$-test, $p>0.05$ ).

\section{Vertical distribution of $T$. similis}

Figure 3 shows the vertical distribution of $T$. similis in greenhouses A (upper panel) and B (lower panel). Most mites inhabited the $0-5-\mathrm{cm}$ soil layer in both greenhouses throughout the year, and $T$. similis was collected from this layer in every month of the year.

\section{DISCUSSION}

In a preliminary experiment, we confirmed that invader mites that could have been carried into the greenhouses in organic fertilizers or other materials were not present from May to December in 1997. Thus, the mite population could be maintained only in or around the greenhouse soil throughout the year, without immigrants, although mite numbers decreased dramatically in the hot months. This population decrease in summer may be influenced by weather conditions and, in partic- 
ular, temperature. Tyrophagus similis is adapted to low temperatures and is not able to live under hightemperature conditions (Kasuga and Amano, 2000a).

The occurrence of large numbers of mites in the uncultivated peripheral soil shows that the greenhouse soil is more important than the spinach plant to the mite life. The ratios of mite numbers in the cultivated and peripheral soils differed between the two greenhouses. It is assumed that the repellent effect observed with the DCIP granules in the cultivated soil affects the mite distribution; we had observed a potentially repellant effect of DCIP under laboratory conditions (Kasuga and Amano, 2003). In greenhouse $\mathrm{A}$, mites in the cultivated soil might have tried to escape to the greenhouse periphery when DCIP granules were applied at $30 \mathrm{~kg} / 1,000$ $\mathrm{m}^{2}$. This possible repellent effect has also been confirmed with phenthoate EC (Kasuga and Amano, 2003). Temporal changes in the vertical distribution of the mites in late November after the application of phenthoate might indicate that this chemical has a repellent effect like that of DCIP.

The soil outside, adjacent to the greenhouse, would seem to be an uncomfortable habitat for mites, because only small numbers of $T$. similis were collected there throughout the year. The humidity levels of this outside soil are probably more unstable than those of the soil in the greenhouse. Tyrophagus similis prefers humid conditions and cannot live in dry conditions (Kasuga and Amano, 2000a). Another possibility is that the food supply in the outside soil is not suitable for mites because they feed on organic fertilizer and plant detritus in greenhouse soil (Kasuga and Amano, 2003). We assumed that the outside area is only a temporary stop for the mites, not the main control point. Our results suggest that the mites in the cultivated and peripheral soils need to be controlled. The mites in the peripheral soil were probably able to move to the cultivated soil and damage the spinach plants, even if the mites in the cultivated soil had been controlled.

Rhizoglyphus robini Claparède, the most famous mite pest in the family Acaridae, also inhabits agricultural soils. Although R. robini and T. similis be- long to the same family and are pests in the same soils, their ecologies differ from each other. For instance, the vertical distribution of $R$. robini is closely related to that of the host plant and the mite inhabits the $0-40-\mathrm{cm}$ soil layer in greenhouses (Takai, 1983). On the other hand, the distribution of $T$. similis is not related to that of the host plant and its habitat layer is shallower than that of $R$. robini. This discrepancy is due to a difference in their feeding preferences: the former prefers bulbs in the soil, whereas the latter organic matter on, or in, the soil. Therefore, control measures for T. similis should be applied intensively in the $0-5-\mathrm{cm}$ soil layer in greenhouses, and sampling and monitoring for assessing $T$. similis density is sufficient at a soil depth of $0-5-\mathrm{cm}$.

\section{ACKNOWLEDGEMENTS}

We are grateful to Mr. Kiyoharu Shibuya for his advice and for the use of his spinach greenhouses. We also thank Mr. Masanori Shimakawa and Ms. Haruka Kanno of Chiba University for their help with the field collections.

\section{REFERENCES}

Kasuga, S. and H. Amano (2000a) Influence of temperature on the life history parameters of Tyrophagus similis Volgin (Acari: Acaridae). Appl. Entomol. Zool. 35: $237-244$

Kasuga, S. and H. Amano (2000b) Survey for the genus Tyrophagus and its damage in spinach crop with view to develop its pest management strategy. J. Acarol. Soc. Jpn. 9: 31-42 (in Japanese with English summary).

Kasuga, S. and H. Amano (2003) Seasonal prevalence and susceptibility to agrochemicals of Tyrophagus similis (Acari: Acaridae) in spinach buds and agricultural soil under greenhouse conditions. Exp. Appl. Acarol. 30: 279-288.

Nakao, H. (1989) Studies on acarid mites (Acari: Astigmata) injurious to vegetable plants. I. Occurrence of damage to spinach by acarid mites. Bull. Hokkaido Prefect. Agric. Exp. Stn. 59: 41-47 (in Japanese with English summary).

Nakao, H. (1996) Ecology and key species of acarid mites injurious to vegetable plants. In Principles of Plant Ac$\operatorname{arology}$ (S. Ehara and N. Shinkaji eds.). Zenkoku-nouson-kyouiku-kyoukai, Tokyo, pp. 292-300 (in Japanese).

Takai, M. (1983) Ecology and control of the bulb mite, Rhizoglyphus robini Claparède, in plastic-house.1. Seasonal prevalence. Bull. Kochi Inst. Agric. Forest Sci. 15: 53-58 (in Japanese). 